\title{
EXISTENCE OF POSITIVE SOLUTION AND NEW OSCILLATION CRITERIA FOR NONLINEAR FIRST-ORDER NEUTRAL DELAY DIFFERENTIAL EQUATIONS
}

\author{
SHYAM SUNDAR SANTRA
}

Abstract. In this work, oscillatory behaviour of the solutions of a class of nonlinear first-order neutral delay differential equations of the form

$$
(x(t)+p(t) x(t-\tau))^{\prime}+q(t) H(x(t-\sigma))=f(t)
$$

and

$$
(x(t)+p(t) x(t-\tau))^{\prime}+q(t) H(x(t-\sigma))=0
$$

are studied under various ranges of $p(t)$. Sufficient conditions are obtained for existence of bounded positive solutions of $\left(E_{1}\right)$.

Mathematics subject classification (2010): 34C10, 34C15, 34K40.

Keywords and phrases: oscillation, nonoscillation, non-linear, delay, neutral differential equations, asymptotic behaviour, existence of positive solution, Knaster-Tarski fixed point theorem, Banach fixed point theorem.

\section{REFERENCES}

[1] F. N. Ahmed, R. R. Ahmad, U. K. S. Din and M. S. M. Noorani, Oscillation criteria of first order neutral delay differential equations with Variable Coefficients, Abst. Appl. Anal., Vol. 2013, Article ID 489804, http://dx.doi.org/10.1155/2013/489804

[2] F. N. Ahmed, R. R. Ahmad, U. K. S. Din and Mohd. S. M. Noorani, Oscillations for Nonlinear Neutral Delay Differential Equations with Variable Coefficients, Abstract and Applied Analysis., Volume 2014, Article ID 179195, http://dx.doi.org/10.1155/2014/179195.

[3] F. N. Ahmed, R. R. Ahmad, U. K. S. Din and M. S. M. Noorani, Oscillation criteria for nonlinear functional differential equations of neutral type, J. Inequ. Appl., DOI 10.1186/s13660-015-0608-5 (2015), 2015:97.

[4] L. Berezansky and E. Braverman, Oscillation criteria for a linear neutral differential equation, J. Math. Anal. Appl. 286 (2003), 601-617.

[5] P. Das and N. Misra, A necessary and sufficient condtion for the solutions of a functional differential equation to be oscillatory or tend to zero, J. Math. Anal. Appl., 204(1997), pp. 78-87.

[6] L. H. Erbe, Q. Kong and B. G. Zhang, Oscillation Theory for Functional-Differential Equations. Marcel Dekker, Inc., New York, (1995).

[7] E. M. Elabbasy, T. S. Hassan and S. H. Saker, Oscillation criteria for first-order nonlinear neutral delay differential equations, Electronic Journal of Differential Equations., Vol. 2005 (2005), No. 134, pp. 1-18.

[8] I. Gyori and G. Ladas, Oscillation Theory of Delay Differential Equations with Applications, Oxford University press., (1991).

[9] J.R. Graef, R. Savithri and E. Thandapani, Oscillation of First Order Neutral Delay Differential Equations, Electronic journal of qualitative theory of differential equations., Proc. 7th Coll. QTDE, (2004), No. $121-11$.

[10] J.K. Hale, Theory of Functional Differential Equations, Spinger, New York(1977). 
[11] I. Kubiaezyk and S.H. Saker, Oscillation of solutions to neutral delay differential equations, Math. Slovaca., 52 (2002), No. 3, pp. 343-359.

[12] I. Kubiaczyk, S.H. Saker and J. Morchalo, New oscillation criteria for first order nonlinear neutral delay differential equations, Appl. Math. Compu., 142 (2003), 225-242.

[13] B. Karpuz and O. Ocalan, Oscillation criteria for some classes of linear delay differential equations of first-order, Bulletin of the Institute of Mathematics, Academia Sinica (New Series)., Vol. 3 (2008), No. 2, pp. 293-314.

[14] B. Liu and L. Huang, Existence and uniqueness of periodic solutions for a kind of first order neutral functional differential equations, J. Math. Anal. Appl., 322 (2006), 121-132.

[15] Z. Liu, S.M. Kangb and J.S. Ume, Existence of bounded nonoscillatory solutions of first-order nonlinear neutral delay differential equations, Computers and Mathematics with Applications., 59 (2010), $3535-3547$.

[16] G. Liu and J. Yan, Global asymptotic stability of nonlinear neutral differential equation, Commun Nonlinear Sci Numer Simulat., 19 (2014) 1035-1041.

[17] H.A. El-Morshedy, On the distribution of zeros of solutions of first order delay differential equations, Nonlinear Analysis: Theory, Methods and Applications., 74 (2011), 3353-3362.

[18] N. Parhi and R.N. Rath, On oscillation and asymptotic behaviour of solutions of forced first order neutral differential equations, Indian Acad. Sci, (Math. Sci.), Vol. III, No. 3, Aug (2001), pp. 337350 .

[19] N. Parhi and R.N. Rath, Oscillation criteria for forced first order neutral differential equations with variable coefficients, J. Math. Anal. Appl., 256 (2001), 525-541.

[20] X. H. Tang, Oscillation for first-order nonlinear delay differential equations, J. Math. Anal. Appl., 264 (2001), 510-521.

[21] X.H. Tang and J.S. Yu, Linearized oscillation of first-order nonlinear neutral delay differential equations, J. Math. Anal. Appl., 258 (2001), 194-208.

[22] S. Tanaka, Oscillation of solutions of first-order neutral differential equations, Hiroshima Math. J. 32 (2002), 79-85.

[23] X. H. Tang and X. Lin, Necessary and sufficient conditions for oscillation of first order nonlinear neutral differential equations, J. Math. Anal. Appl., 321 (2006), 553-568.

[24] X. Zhang and J. Yan, Oscillation criteria for first order neutral differential equations with positive and negative coefficients, J. Math. Anal. Appl., 253 (2001), 204-214.

[25] W.P. Zhang, W. Feng, J.R. Yan and J.S. Song, Existence of Nonoscillatory Solutions of First-Order Linear Neutral Delay Differential Equations, Computers and Mathematics with Applications, 49 (2005), 1021-1027. 